\title{
Short communication: Changes in heart rate variability of dairy cows during conventional milking with nonvoluntary exit
}

\author{
L. Kovács, ${ }^{* 1}$ J. Tőzsér, ${ }^{*}$ M. Bakony,† and V. Jurkovich \\ *Institute of Animal Husbandry, Faculty of Agricultural and Environmental Science, Szent István University, Páter K. utca 1, Gödöllö 2103, \\ Hungary \\ †Rumino-Vet Bt, Csillés utca 2, Érd 2030, Hungary \\ ‡Department of Animal Hygiene, Herd Health and Veterinary Ethology, Faculty of Veterinary Science, Szent István University, István utca 2, \\ Budapest 1078, Hungary
}

\begin{abstract}
Heart rate variability (HRV), as a physiological measure of animal welfare, was investigated in 36 cows milked in a parallel milking parlor with nonvoluntary exit. Heart rate variability parameters measured during the morning resting (baseline period) were compared with those measured during different stages of the entire milking process. No differences were found in HRV parameters between the baseline period, preparation, and main milking. A considerable reduction in vagal activity was detected during the movement of the cows to the milking parlor (driving) and while cows were in the holding area. The parasympathetic measures of HRV decreased whereas the sympatho-vagal balance increased compared with baseline. The same pattern was observed regarding the stage between removing the teat cups and leaving the milking parlor (waiting). No differences in any sympathetic measures were observed between the baseline period and any of the milking stages. These findings indicate that the milking process itself (preparation and main milking) is not stressful for cows. Decreased parasympathetic activity during driving might be the result of the physical activity of the cows, whereas waiting in the holding area and in the milking stall after milking caused stress for animals. Key words: heart rate variability, dairy cow, milking stage, stress
\end{abstract}

\section{Short Communication}

In intensive cattle farming, it is of particular interest to identify physiological indicators that describe the animal's responsiveness to stressors. Besides hypothalamus-pituitary-adrenal axis measures and heart rate measurements, heart rate variability $(\mathbf{H R V})$ is an alternative measure that has been used recently for the

Received May 16, 2013.

Accepted September 2, 2013.

${ }^{1}$ Corresponding author: kovacs.levente@mkk.szie.hu evaluation of stress responses in dairy cows (Konold et al., 2011; Kovács et al., 2012b). Heart rate variability is defined as the oscillation in the length of the time interval between consecutive heart beats (interbeat interval, IBI), which are nonuniformly separated over time.

Stressful stimuli are known to cause a decrease in parasympathetic activity (Porges, 2003) and changes in the sympatho-vagal balance (von Borell et al., 2007). With certain parameters of HRV, the activity of the sympathetic (SNS) and parasympathetic (PNS) nervous system can be monitored separately (ESC-NASPE Task Force, 1996). The effects of technological factors on the autonomic nervous system (ANS) have been reported in dairy cattle using parasympathetic and sympatho-vagal indices of HRV (Mohr et al., 2002; Hagen et al., 2005; Kovács et al., 2012b). Alterations in HRV measures sensitive to PNS modulation or representing sympatho-vagal balance allow a detailed interpretation of stress in different situations of dairy management.

Several methods have been proposed for the assessment of HRV as reviewed by von Borell et al. (2007) in farm animals and by Kovács et al. (2012a) in dairy cattle, specifically. Power spectral analysis of HRV helps to identify components that characterize the sympatho-vagal balance. The low frequency component (LF) depends on the baroreceptor modulation of both vagal and sympathetic impulses, and has been used as an indicator of stress in dairy calves (Stewart et al., 2008) and cows (Mohr et al., 2002; Hagen et al., 2005; Konold et al., 2011).

The high frequency (HF) component reflects the vagal control of the heart (Akselrod et al., 1985) and has been used in studies involving dairy cows (Hagen et al., 2005; Konold et al., 2011). In itself, measuring the heart rate does not allow us to distinguish the effects of the individual branches of the ANS (Hainsworth, 1995), because an increase in heart rate may originate from reduced vagal or increased sympathetic activity, or possibly from simultaneous changes in the activity of both branches (von Borell et al., 2007). Nonlinear Poincaré measures and time domain parameters of 
HRV - especially root mean square of successive IBI differences (RMSSD) - have recently been used in dairy cattle studies (Minero et al., 2001; Kovács et al., $2012 \mathrm{~b}$ ) and found to be successful in assessing the vagal regulation of cardiac dynamics, which plays a key role in response to stress (von Borell et al., 2007).

Heart rate variability has been used in welfare research to gain information about the stress dairy cows might experience during milking. Gygax et al. (2008) found higher levels of stress (lower parasympathetic tone during milking compared with resting) in cows milked in an automatic milking system (AMS) than in cows milked in an auto-tandem milking parlor, whereas others noted lower stress levels in an AMS than in a herringbone milking parlor (Hagen et al., 2005). No research has been done in evaluating stressrelated changes of HRV in parallel milking parlors with nonvoluntary exit (a commonly used system in central Europe) during each of the stages involved in the whole process of milking. Thus, the objective of the present study was to investigate the changes of HRV in dairy cows during milking in a conventional system with nonvoluntary exit.

Thirty-six (primiparous, $\mathrm{n}=18$ and multiparous, $\mathrm{n}$ $=18$ ) lactating Holstein-Friesian cows (mean $\pm \mathrm{SD}$; parity $=2.42 \pm 1.12$ lactation; daily milk production $=38 \pm 6.2 \mathrm{~kg} ; \mathrm{DIM}=150 \pm 10 \mathrm{~d}$ ) were selected from clinically healthy animals (mean $\pm \mathrm{SD}$; $\mathrm{BCS}=2.48$ \pm 0.32 , locomotion score: $1.52 \pm 0.36)$ for this study. Cows were housed in modern freestall barns with individual stalls bedded with straw in a large dairy farm in Jászapáti, Hungary. Cows were fed TMR twice a day at 0700 and $1600 \mathrm{~h}$ and had ad libitum access to water. Cows were milked 3 times a day in a $2 \times 24$ Bou-Matic parallel milking system (Bou-Matic, Madison, WI) at approximately 0400, 1200, and $1900 \mathrm{~h}$. The experiment was carried out in May 2012 during a 2-wk period (each day from 0630 to $2130 \mathrm{~h}$ ) under normal weather conditions (mean $\pm \mathrm{SD}$; temperature: $16.4 \pm 6.7^{\circ} \mathrm{C}$ ).

Each cow was in the trial for 3 consecutive days. The trial was split into 3 periods as follows: (1) habituation: the heart rate monitoring systems that stored IBI for about $15 \mathrm{~h}$ continuously (Polar Equine RS800 CX, Polar Electro Oy, Helsinki, Finland) were attached to the cows by using a specially designed girth on $\mathrm{d}$ 1 ; and the cows were given a 1-h habituation period before starting the experiment (starting time: $0730 \mathrm{~h}$ ); (2) baseline: from d 1 to 3 , each morning from 0830 to $1130 \mathrm{~h}$, baseline HRV data were recorded during lying (resting bouts); and (3) milking process: from d 1 to 3 , HRV data were collected twice a day during the midday and evening milkings for each of the milking process stages (Table 1). Two video cameras (Legria HF M36, Canon, Tokyo, Japan) were installed, one in the hold- ing area and one in the parlor to help match milking stages and HRV recordings. Information on the length of milking stages was collected based on the video time signal. Focal cows were identified by the numbers on their hind legs and backs drawn on at the time of fixing the girths.

Heart rate variability parameters during lying (baseline data) were recorded by direct observation in 5-min time windows, following recommendations of earlier studies (Mohr et al., 2002; Hagen et al., 2005). Moments of lying down, standing up, and any kind of disturbance (e.g., sudden noise, handler walking close by) were perceivable in the heart rate data; thus, undisturbed bouts (2-5/cow per day) could be evaluated, starting from 5 min after the cow had lain down. Because it is advised to use data bouts of the same length for the comparison of HRV measures (ESC-NASPE Task Force, 1996), the first 5 min of recordings during each milking stage were used, following the practice of Gygax et al. (2008). In case of stages exceeding 10 min in length (e.g., driving and being in the holding pen), the last 5 min of recordings were also included in analysis. Because of the large number of animals being milked simultaneously $(2 \times$ 24 ), preparation and waiting times were, in most cases, sufficiently long for reliable HRV analysis.

The IBI data were imported into the Kubios HRV 2.0 software (Niskanen et al., 2004) for artifact inspection and HRV analysis. The errors in IBI data during resting and milking bouts were corrected using the algorithm provided by the software.

A total of 4 to 6 milkings per cow were analyzed in the course of the experiment. Data loss was encountered because of technical problems (e.g., damaged belts, dried out electrodes, or flat batteries in heart rate receivers).

We calculated parameters of HRV in time and frequency domains and by nonlinear methods (Table 2 ). For frequency-domain analysis, a power spectrum method developed by Akselrod et al. (1981) was used based on fast Fourier transformation. Recommendations of von Borell et al. (2007) were considered by setting the limits of the spectral components as follows: LF: $0.05-0.20 \mathrm{~Hz}$, and HF: $0.20-0.58 \mathrm{~Hz}$, which were calculated in normalized units $\left(\mathbf{L F}_{\text {norm }}\right.$ and $\left.\mathbf{H F}_{\text {norm }}\right)$. Poincaré plots were calculated according to the methodology described by Minero et al. (2001).

A generalized linear model (SPSS 18, SPSS Inc., Chicago, IL) was used to determine the effects of milking stages (factors), parity, and milk production (possible confounding effects) on HRV parameters (response variables). Data for a given cow were compared with the baseline data of the same cow. To account for the repeated milkings of the cows, an individual cow was included as a random effect in the model. The residuals 
Table 1. Studied periods and number of bouts involved in heart rate variability analysis

\begin{tabular}{|c|c|c|c|}
\hline \multirow[b]{2}{*}{ Phase } & \multirow[b]{2}{*}{ Definition } & \multicolumn{2}{|c|}{$\begin{array}{l}\text { No. of analyzed } 5 \text {-min } \\
\text { intervals per cow }\end{array}$} \\
\hline & & Per milking & In total \\
\hline Driving & Time lag between letting out of the stable gate and entering the holding area & $1-2$ & $3-5$ \\
\hline Being in the holding area & Time interval between entering the holding area and stepping into the milking parlor & $1-3$ & $5-9$ \\
\hline Preparation & $\begin{array}{l}\text { Admission time }+ \text { udder preparation time } \\
\text { Admission time = time interval between entering the milking stall and the beginning of udder preparation } \\
\text { Udder preparation }=\text { first contact between animal and milker until attachment of all teat cups }\end{array}$ & 1 & $4-6$ \\
\hline Main milking & Time interval between the attachment and the removal of the last teat cup & 1 & $4-6$ \\
\hline Waiting after milking & Time interval between the removal of the last teat cup and stepping out of the milking stall with all 4 legs & 1 & $4-6$ \\
\hline $\begin{array}{l}\text { Baseline period } \\
\text { (morning resting) }\end{array}$ & Time spent lying after the morning milking (bouts started 5 min after the cow had lain down) & $2-5$ & $7-12$ \\
\hline
\end{tabular}

(morning resting)

Time interval between the removal of the last teat cup and stepping out of the milking stall with all 4 legs

Time spent lying after the morning milking (bouts started 5 min after the cow had lain down)

Table 2. Classification and definition of the heart rate variability parameters calculated in this study

\begin{tabular}{|c|c|c|c|}
\hline Analysis method & Parameter & Definition & $\begin{array}{l}\text { ANS component } \\
\text { represented }^{1}\end{array}$ \\
\hline Time domain & RMSSD (ms) & Root mean square of successive interbeat interval (IBI) differences & PNS \\
\hline \multirow{3}{*}{ Poincaré plot } & $\mathrm{SD} 1(\mathrm{~ms})$ & Standard deviation of instantaneous IBI variability measured from axis 1 in the Poincaré plot & PNS \\
\hline & $\mathrm{SD} 2(\mathrm{~ms})$ & Standard deviation of long-term continuous IBI variability measured from axis 2 in the Poincaré plot & SNS \\
\hline & $\mathrm{SD} 2 / \mathrm{SD} 1$ & SD2 divided by SD1 & Sympatho-vagal balance \\
\hline \multirow[t]{2}{*}{ Frequency domain } & $\mathrm{HF}_{\text {norm }}$ & Normalized power of the high-frequency band & PNS \\
\hline & $\mathrm{LF}_{\text {norm }}$ & Normalized power of the low-frequency band & SNS \\
\hline
\end{tabular}

${ }^{1} \mathrm{ANS}=$ autonomic nervous system; PNS $=$ parasympathetic nervous system; SNS = sympathetic nervous system. 
of the model were inspected graphically for distribution and homogeneity of variances. The HRV parameters were subjected to logarithmic transformations before analysis. Pairwise differences between the milking stages were tested by the Bonferroni post hoc test.

Parameters of HRV during the baseline period and milking stages are summarized in Table 3. During the stage of driving, RMSSD, $\mathrm{HF}_{\text {norm }}$, and the standard deviation of instantaneous IBI variability measured from axis 1 in the Poincaré plot (SD1) were lower $(P$ $<0.001$ ) and the standard deviation of instantaneous IBI variability measured from axis 2 in the Poincaré plot (SD2) divided by SD1 was higher $(P<0.05)$ than baseline values. The same pattern was observed during the stage when cows were in the holding area: the PNSassociated parameters (RMSSD, $\mathrm{HF}_{\text {norm }}$, and SD1) were lower $(P<0.01, P<0.01$, and $P<0.001$, respectively) and SD2/SD1 was higher $(P<0.05)$ compared with the baseline period. During preparation and the main milking, we observed no differences in any of the studied HRV parameters compared with the baseline period. During the stage of waiting after milking, significant changes were detected for RMSSD, $\mathrm{HF}_{\text {norm }}$, and SD1, which were lower $(P<0.05, P<0.01$, and $P<0.001$, respectively), and for SD2/SD1, which was higher $(P<$ 0.01) than baseline data. Regarding SD2 and $\mathrm{LF}_{\text {norm }}$, no differences were found between the baseline period and any of the milking stages.

The evaluation of HRV parameters is an important measure for assessing cow welfare and comfort, because it allows evaluation of stress levels during different situations that occur daily on farms, such as milking (Hagen et al., 2005; Neuffer, 2006; Gygax et al., 2008), during disease (Konold et al., 2011), and events related to production (Mohr et al., 2002). However, research related to milking has previously focused only on systems that were automatic or had voluntary exit.
The significant reduction in PNS activity during driving either equates to considerable stress or resulted from the moving of the animals. Cows find some handling methods to be aversive (Pajor et al., 2000). In our study, only the cows at the end of the row were motivated to speed up their movement during driving, usually vocally by the stockperson. To eliminate effects of the direct human interaction, data of 3 affected focal animals were excluded from analysis.

A decrease in PNS activity, as represented by reduced vagal tone and a shift in sympatho-vagal balance measured in the holding area, indicates an increased level of stress. Because cows were allowed to enter the parlor on their own (not forced), stress was presumably a result of crowding in the holding area.

Recent studies found slightly increased stress levels in cows milked in AMS during milking (Neuffer, 2006; Gygax et al., 2008). However, we found that the milking process itself was not stressful for cows. In our study, HRV parameters indicated a greater level of stress during the stages around milking (driving, being in the holding area, and waiting after milking) but not during milking itself (udder preparation and main milking; lower $\mathrm{HF}_{\text {norm }}$, RMSSD, and SD1, and higher SD2/ SD1) compared with resting (baseline). In agreement with these results, Hagen et al. (2005) found no effects of the milking system (AMS and herringbone milking parlor) on HRV, suggesting the absence of stress during the milking process, and neither udder preparation nor milking was stressful for cows. The predominance of PNS on cardiac activity (higher $\mathrm{HF}_{\text {norm }}$ ) during udder preparation and the main milking stages might have resulted from oxytocin release, which induces an increase in the vagal nerve activity (Uvnäs-Moberg and Petersson, 2005).

Heart rate variability parameters during waiting after milking reflected a significant stress load. Decreased

Table 3. Heart rate variability (HRV) parameters during lying and milking stages ${ }^{1}$

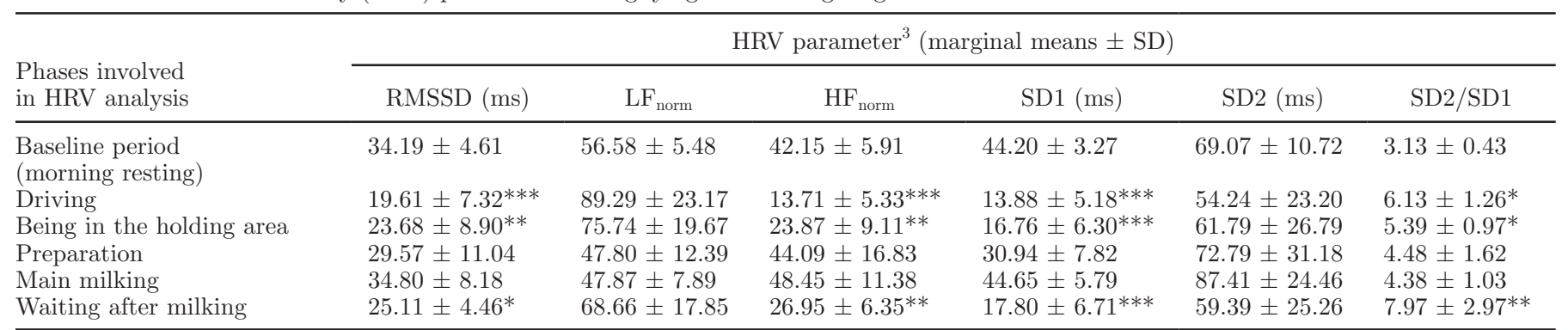

${ }^{1}$ Descriptive statistics are based on individuals' means of log-transformed data.

${ }^{2} \mathrm{RMSSD}=$ root mean square of successive interbeat interval $(\mathrm{IBI})$ differences; $\mathrm{LF}_{\text {norm }}=$ normalized power of the low-frequency band; $\mathrm{HF}_{\text {norm }}=$ normalized power of the high-frequency band; SD1 = standard deviation of instantaneous IBI variability measured from axis 1 in the Poincaré plot; SD2 = standard deviation of long-term continuous IBI variability measured from axis 2 in the Poincaré plot.

${ }^{*} P<0.05,{ }^{* *} P<0.01,{ }^{* * *} P<0.001$ (differences between milking stages and the baseline period). 
PNS activity is thought to be related to the degradation of the released oxytocin or restlessness due to confinement. Earlier studies of Hagen et al. (2005) and Gygax et al. (2008) involving milking systems with voluntary exit did not evaluate this stage of the milking process, because of the short period that cows spent waiting in an AMS, or the focus being placed on milking itself in a herringbone milking parlor.

The limitation of our study lies in the fact that the applied methodology (ESC-NASPE Task Force, 1996; Mohr et al., 2002; von Borell et al., 2007) did not allow us to compare HRV parameters of animals that spent at least 5 min waiting with HRV parameters of those that spent less time, and thus, the latter were excluded from analysis. Therefore, the HRV analysis regarding the stage of waiting might not be representative for all animals milked in our study.

In accordance with other reports (Mohr et al., 2002; Hagen et al., 2005), SNS parameters ( $\mathrm{LF}_{\text {norm }}$ and SD2) showed no differences between resting and any of the studied milking stages. However, $\mathrm{LF}_{\text {norm }}$ was considered a poor marker of SNS activity in an earlier study, because it is partially under vagal influence (Houle and Billman, 1999).

In view of our findings, it is worth investigating the importance of stress caused by crowding or occurring during waiting after milking and its effect on animal welfare. The large size of milking parlors reduces the time spent in the holding areas (Bickert et al., 1974) but can elongate the period of waiting after milking in nonvoluntary exit commercial parlors, entailing significant stress.

\section{ACKNOWLEDGMENTS}

This research was supported by the European Union and the State of Hungary, co-financed by the European Social Fund in the framework of TÁMOP 4.2.4. A/-111-2012-0001 National Excellence Program.

\section{REFERENCES}

Akselrod, S., D. Gordon, J. B. Madwed, N. C. Snidman, D. C. Shannon, and R. J. Cohen. 1985. Hemodynamic regulation: Investigation by spectral analysis. Am. J. Physiol. 249:867-875.

Akselrod, S., D. Gordon, F. A. Ubel, D. C. Shannon, A. C. Berger, and R. J. Cohen. 1981. Power spectrum analysis of heart rate fluctuation: A quantitative probe of beat-to-beat cardiovascular control. Science 213:220-222.
Bickert, W. G., J. A. Speicher, and D. V. Armstrong. 1974. Milking systems for large herds. J. Dairy Sci. 57:369-377.

Gygax, L., I. Neuffer, C. Kaufmann, R. Hauser, and B. Wechsler. 2008. Restlessness behaviour, heart rate and heart-rate variability of dairy cows milked in two types of automatic milking systems and auto-tandem milking parlours. Appl. Anim. Behav. Sci. 109:167-179.

Hagen, K., J. Langbein, C. Schmied, D. Lexer, and S. Waiblinger. 2005. Heart rate variability in dairy cows-Influences of breed and milking system. Physiol. Behav. 85:195-204.

Hainsworth, R. 1995. The control and physiological importance of heart rate. Pages 3-19 in Heart Rate Variability. M. Malik and A. J. Camm, ed. Futura Publishing, Armonk, NY.

Houle, M. S., and G. E. Billman. 1999. Low-frequency component of the heart rate variability spectrum: A poor marker of sympathetic activity. Am. J. Physiol. 276:H215-H223.

Konold, T., G. E. Bone, and M. M. Simmons. 2011. Time and frequency domain analysis of heart rate variability in cattle affected by bovine spongiform encephalopathy. BMC Res. Notes 4:259.

Kovács, L., K. Nagy, Z. Szelényi, O. Szenci, and J. Tőzsér. 2012a. Heart rate variability as a measure of stress in cattle: Biological background, methods of measurement and results-A review. Magy. Állatorv. Lapja 134:515-523. (In Hungarian)

Kovács, L., K. Nagy, O. Szenci, and J. Tözsér. 2012b. Heart rate variability during milking in dairy cows. Magy. Állatorv. Lapja 134:653-661. (In Hungarian)

Minero, M., E. Canali, V. Ferrante, and C. Carenzi. 2001. Measurement and time domain analysis of heart rate variability in dairy cattle. Vet. Rec. 149:772-774.

Mohr, E., J. Langbein, and G. Nürnberg. 2002. Heart rate variability: A noninvasive approach to measure stress in calves and cows. Physiol. Behav. 75:251-259.

Neuffer, I. 2006. Influence of automatic milking systems on behaviour and health of dairy cows. PhD Thesis. University of Hohenheim, Hohenheim, Germany.

Niskanen, J. P., M. P. Tarvainen, P. O. Ranta-Aho, and P. A. Karjalainen. 2004. Software for advanced HRV analysis. Comput. Methods Programs Biomed. 76:73-81.

Pajor, E. A., J. Rushen, and A. M. B. de Pasillé. 2000. Aversion learning techniques to evaluate dairy cattle handling practices. Appl. Anim. Behav. Sci. 69:89-102.

Porges, S. W. 2003. The polyvagal theory: Phylogenetic contributions to social behavior. Physiol. Behav. 79:503-513.

Stewart, M., K. J. Stafford, S. K. Dowling, A. L. Shaefer, and J. R. Webster. 2008. Eye temperature and heart rate variability of calves disbudded with or without local anaesthetic. Physiol. Behav. 93:789-797.

ESC-NASPE Task Force (Task Force of the European Society of Cardiology and the North American Society of Pacing and Electrophysiology). 1996. Heart rate variability: Standards of measurement, physiological interpretation and clinical use. Circulation 93:1043-1065.

Uvnäs-Moberg, K., and M. Petersson. 2005. Oxytocin, ein Vermittler von Antistress, Wohlbefinden, sozialer Interaktion, Wachstum und Heilung. Zeitschr. Psychosom. Med. Psychother. 51:57-80.

von Borell, E., J. Langbein, G. Després, S. Hansen, C. Leterrier, J. Marchant-Forde, R. Marchant-Forde, M. Minero, E. Mohr, A. Prunier, D. Valance, and I. Veissier. 2007. Heart rate variability as a measure of autonomic regulation of cardiac activity for assessing stress and welfare in farm animals: A review. Physiol. Behav. 92:293-316. 